\begin{tabular}{|c|c|}
\hline \multirow{3}{*}{ 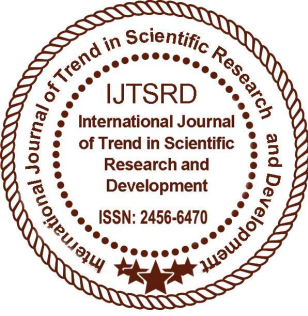 } & $\begin{array}{l}\text { International Journal of Trend in Scientific } \\
\text { Research and Development (IJTSRD) }\end{array}$ \\
\hline & International Open Access Journal \\
\hline & ISSN No: 2456 - 6470 | www.ijtsrd.com | Volume - 2 | Issue - 4 \\
\hline
\end{tabular}

\title{
Internet of Things (Iot) Based Smart Environment and its Applications
}

\author{
Devi Kala Rathinam. D, Sherin. J, Santhiya Grace. A \\ PG Scholar, Department of Computer Science and Engineering \\ Sri Krishna College of Engineering and Technology \\ Coimbatore, Tamil Nadu, India
}

\section{ABSTRACT}

In day to day world the internet of things is one of the emerging technologies. Through wired and wireless medium IOT connects various object which helps the human to interact with objects in both digital as well as physical world. Due to increase of population the services are very challenging for the providers. To overcome those challenges the IOT has developed with many applications. IOT contain the sensor which connects to Bluetooth, Wi-Fi, RFID and also it covers wide area with many technologies like GSM, 3G and GPRS. The IOT devices collect many useful information from various devices and flow the data between many devices. The flow of information can be done without human-to-human or human-tocomputer interaction. Due to IOT the world will become smart so it is called as smart home, smart cities, smart building and also some applications. Many sectors are connected to RFID technologies like banking, agriculture, education, domestic appliances monitoring, Surveillances, government - e services, government - e services, traffic surveillance, meteorology and security and emergency. This devices also consist of heat, light, security system with less cost. The online capable devices figure was $31 \%$ in 2016 . It increased up to 8.4 billion in 2017. The IOT devices will be increased more than 30 billion in the year of 2020. The value of IOT will reach nearly up to $\$ 7.1$ trillion. In 2019 Enterprise internet of things (EIOT) devices increases up to 9.1 billion. In this paper IOT based smart environment is discussed with its issue. It is used for transport, vehicle parking, waste management, reduce traffic, increase the better communication with road side objects like hospital, school and also with other objects.

Keywords: Smart Cities, Smart Buildings, Smart Environment, Smart Energy, Forest, Smart Healthcare, Smart Manufacturing, Waste management

\section{INTRODUCTION}

Internet of things is sometimes said to be internet of object because it change each and every object even our selves. The internet has made numerous changes in communication, transport, government, education, science and business. Internet is one of the important source in all activities of human. The internet of things is one of the important and new technologies in internet accessing. It recognize the object by itself, decision are made by themselves and communicate the information. The objects are combined with other devices. Internet is used by human at anyplace at any time.

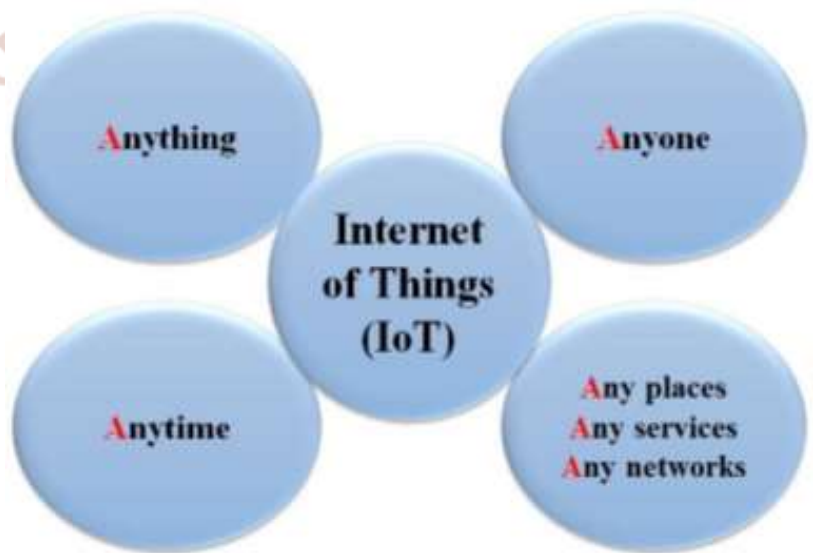

Fig 1: Internet of things 
Anyone can access the IOT from anyplace by using any network. By using wireless sensor anyone can communicate with things or between the things. Based on this the communication can be done with the surrounding objects. The world is digital, virtual and also real it convergence to create the world as smart with transport, energy, cities and also in other fields. This is very important technology used in business and also in our economy. This technology has made the enormous change the way of products and services are distributed. The cities can be changed into a smart cities by reducing the cost of municipal administrations, improving the better use of municipal resources and other features to can be improved to make the smart cities. The IOT is inexpensive, simple and also it provides better communication between the different objects. This includes interoperability, power management, robustness, usability, miniaturization, scalability, security, standardization, communications and management. It is used for object identification, positioning, tracking, monitoring and management in different fields. Some systems are based on data for long time but sometimes there is no network connectivity at that time the data are collected and stored in a laptop. There is a use of internet connectivity it used to send the data directly to the server which helps the user to use the data very effectively. The main aim of creating a Global Environmental based on sensor can be provide by scalable IoT. The data are collected using sensor and combined with other devices. In India new concept 'DIGITAL INDIA' proposed by Prime minister Mr. Narendra Modi which gained momentum due to IoT, it is the hot research area which increasing popularity for government, industry and in education as well. Smart environment includes construction of buildings which has high security, energy savings, health and wellness and integrate personal comfort.

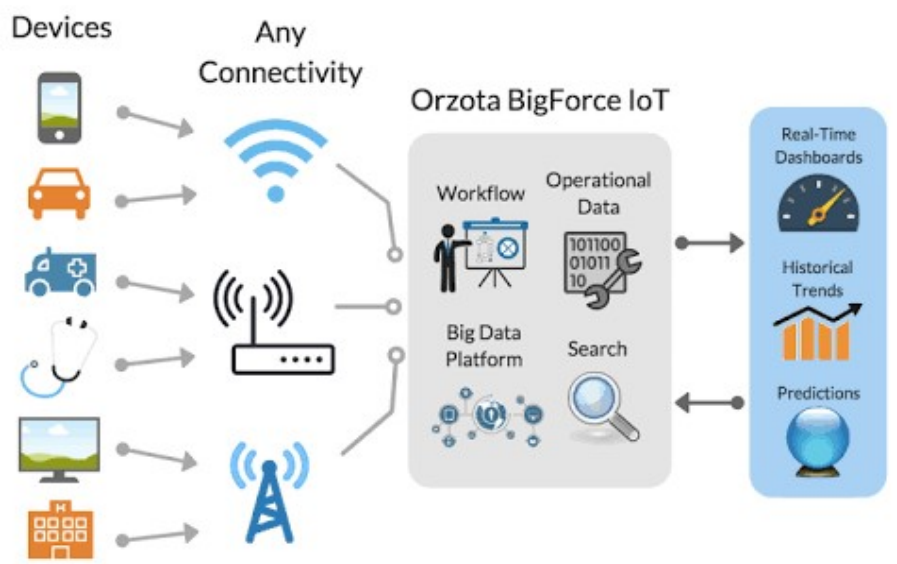

Fig 2: Architecture of internet of things (IoT)
The input devices are smart phones, clothes, laptops, tablets, body nodes, personal computers and some of the portable devices. Those intelligences are embedded into our environment through internet connection to change the traditional environment into smart environment.

\section{Literature Survey}

Vimal Jerald A, Albert Rabara S and Daisy Premila Bai $\mathrm{T}$ proposed the paper on Internet of Things (IoT) based Smart Environment integrating various Business Applications

In this paper the architecture of smart environment is discussed very clearly. The smart environment includes some smart home applications, medical applications, business system, smart agriculture system, smart traffic surveillance, emergency system, smart E-governance system, smart banking system, smart whether monitoring system, smart rescue, Smart public distribution system and smart education system. Some objects are connected to sensors and RFID systems are used to connect to various business applications [1]. The RFID antenna is compromised by RFID system and the information are infer by reader from various domain. Those information are send to further processing and later send through network to IoT based Kendra information. The information Kendra the data is processed where the data is actually inferred. The IoT based Kendra information is based on cloud, billing related services and some of the external services. There are layers four layers in environmental architecture. Layer one is device layer otherwise called as perception layer, second layer is middleware layer, next layer is network layer and final layer is application layer.

\section{Perception layer}

It is also called as device layer. This layer consist of various objects like sensor, RFID tags and some physical objects. Some devices support this layers, devices are sensors, RFID readers and RFID antennas. The information are collected using sensors and RFID tags from various business domains. The information like sound, climatic condition, location, heart pulse, temperature and humidity. Those collected data are send to middle layer

\section{Data Conversion Layer}

Sensor has many heterogeneous signals and RFID tags consist of several tiny devices and those tiny devices are attached to smart environments business 
application. The data can be in the form of heterogeneous signals, those signals are not send directly to network layer for further processing. Most of the signals are in the form analog. The signals are converted into data in this layer and send through the network. It is mainly responsible for converting the analog signals.

\section{Network Layer}

It is also known as transport layer. It is mainly used for fetching the data to IoT kendra for processing. The further decision are made at this layer based on the data, it will be supposed with cloud applications data centre. The function of this layer on network is based on TCP/IP. There are some devices used in this layer like firewalls, routers, servers, gateways and switches.

\section{Application Layer}

In this layer all the decision are made based on the data inferred from the objectsand some devices used in the business domains. Each function is based on different applications and services used in the above layers.

Jayavardhana Gubbi et.al proposed the paper on Internet of Things (IoT): A Vision, Architectural Elements, and Future Directions [2]

In this paper the ubiquitous computing is embedded into the everyday life of human. Our environment gets change due to smart phones, laptops, tablets and other handheld devices. These devices are very interactive and informative in modern world. These devices are connected to internet to give the effective communication between various objects and also with human. The data are stored and it can be accessed by various owners. The ubiquitous computing Can customized by individual or by an organization. It used to change the traditional world into modern world. Two technologies are used mainly for growing the ubiquitous computing one is Cloud Computing and the other one is Internet of Things. The new technology micro-electro-mechanical systems (MEMS) contain wireless communications, and digital electronics are used for development of devices which consist of sense, communicate wirelessly in short distances and compute. The small devices are said to be nodes to form a wireless sensor networks (WSN) and used to find some applications like traffic monitoring, environmental monitoring, retail and infrastructure monitoring etc. Based on the complete IoT vision it is more efficient, scalable, market oriented computing, storage and secure. Cloud computing provide more reliable services based on virtual storage technologies. It act as a receiver to interpret the data and also the user can understand web based visualization. In this computing the sensing and processing are hidden from the user and it works in the background. It is platform-independent, deploy large-scale, wireless sensor network infrastructure which includes data management and processing, analytics and actuation. Cloud computing is scalability, high reliability and dynamic resource discovery, autonomy to provide ubiquitous access and compos ability requires in IoT. The Quality of Service parameters is selected by Consumers.

Shagufta Rajguru .et.al describes about Analysis of Internet of Things in a Smart Environment [3]

In this paper the characteristics of IoT is described. The IoT must have the following characteristics; they are Comprehensive Perception, Reliable Transmission and Intelligent Processing. The smart environment in a city must contain Smart Mobility, Smart Buildings Smart Governance and Smart Utilities.

\section{Monitoring health of buildings}

To maintain a proper environment the buildings must be monitored continuously. Sensors are fixed in a building for continuous monitoring. It maintains the distributed database by the sensor which measure the temperature, humidity, building stress, vibration, pollution levels and so on.

\section{Management of waste}

The waste management is one of the main issue in environmental monitoring. The service cost and garbage storage is one of the main issues in environmental monitoring. Sensor monitor the level of waste present in waste container it used to reduce the cost of waste collection, increase the recycling quality and provide the optimized route for trucks. IoT connects to end devices and the management of optimal truck fleet.

\section{Monitoring quality of air}

In a crowded areas the air quality monitoring is one of the important task. There is park, fitness centre and some outdoor activities will be provided in environment. Some sensors are present in crowded are to monitor the quality of air.

\section{Monitoring Noise}

The noise monitoring is one of the important service provided by IoT in the smart environment. Using 
some noise monitoring tool the noise is monitored at any given hour. The sound detection algorithms are used ere to identify the type of noise detected by noise monitoring tool.

\section{Traffic congestion}

The traffic monitoring is one of the important task done by IoT. In some modern devices GPS installed. It used to forward the information to citizens and traffic authorities for controlling the traffic and also to scheduling the route.

\section{Smart parking}

Road side sensor is used for parking the vehicles which direct the motorist in best path. It used for locate the vehicle in best place with less time. It reduce the traffic congestion, happier citizens and so on. It use short range communication technologies like Radio Frequency Identifiers (RFID) or Near Field Communication (NFC) for better allotment.

\section{Smart lighting}

Based on weather conditions the street light intensity is provided. It is one of the main service provided by smart environment. It work properly by some important sensors.

Zeinab Kamal Aldein Mohammeda, Elmustafa Sayed Ali Ahmedb proposed the paper onInternet of Things Applications, Challenges and Related Future Technologies [4]

In this paper some challenges are discussed. The challenges like Scalability, Self-Organizing, Data interpretation, Data volumes, Interoperability, Fault tolerance, Security and privacy, Automatic Discovery, Software complexity, Power supply and Wireless communications. Smart environment provides services not only to human life but also to birds, plants, fishes and also even for animals. Some effort has been made to reduce the pollution and waste resources. To create a healthy environment it is very important task to monitor the environment. The environment gets affected due to irresponsible human activities. Smart environment provides very useful services for everyday life. The main application provided by Smart environment is water and air pollution, natural disaster, weather and radiation monitoring, waste management and many other environmental factors. Smart environment devices are used for monitoring, analyzing, tracking, sensing, managing natural disaster and radiation monitoring.
Some natural disasters can also managed by Smart environment, they are forests, freshwater, land, fishes, petroleum, coal and some metals like copper, iron and gold. Internet of things can be combined with some of the upcoming technologies like Cloud Computing, Big Data, Security and Privacy, Distributed Computing and Fog Computing.

Jane K. Hart and Kirk Martinez proposed the paper toward an environmental Internet of Things [5]

In this paper the explained about environmental monitoring and hazard warnings. The properties of earth are not monitored properly. Number of sensors are used to provide hazard warnings and lightning detection during the occurrence of natural hazards like tsunamis warning. The devices used for environmental monitoring is distributed to many places for monitoring. It is very difficult to distribute the devices. While distributing the devices we can increase the energy and resources. Small dust available in environment are very difficult to remove. The IoT provides the seamless data stream from the web. Sensor nodes are designed to adapt environmental conditions and power availability with low cost.

Bhoomika.K.N.et.al proposed the paper on Internet of Things for Environmental Monitoring

In this paper they discussed about few factors of environmental monitoring. Those few factors are vehicle parking, temperature and waste management. These factors are used in our day to day life. [6]

\section{Waste Management}

In major cities the waste management is one of the main issue. It is mainly due to cost of the service and the problem of the waste storage. The intelligent waste containers is used to monitor the level of waste and allow the truck to have optimal route and provide reduce the cost for waste management. It increase the recycling quality [7]. IoT contain the devices for waste monitoring it is integrated with the container and the software can decide the further process and determine the garbage collection in the truck used for collecting the garbage.

\section{Temperature}

In future IoT plays major role in all the cities. Air quality measurement is one of the important process in environmental monitoring. The temperature 
measurement is done through sensor. But the temperature changes from at each time and at different places [8]. The level of temperature varies at night compared to day. In our surrounding there is a high content of Nitrogen-di-oxide (NO2) and Carbon monoxide $(\mathrm{CO})$.

\section{Vehicle Tracking}

Some sensors are fixed on roadside it track the vehicle and provide the optimal route to the drivers. It used to monitor the traffic signals, parking and other services can be provided by this sensor. The sensor for vehicle parking device is integrated with the IoT infrastructure. The communication can be done through Radio Frequency Identifiers (RFID) for parking the car in a reserved slot [9]. It provide a better service for parking and traffic signals are managed by this sensor.

Dr. A. Sumithra .et.al proposed the paper on a smart environmental monitoring system using internet of things [10]

The smart city can improve the life quality, efficiency, services and so on. Communication between various devices can improve the quality of life. Smart city can have various characteristics like Smart Economy, Smart Governance, Smart Living, Smart People and Smart Environment and Smart Mobility. Here app is developed for estimating the pollution. The level of air is estimated and if the level is more than the normal level the information is send to higher authorities. The environment monitoring used to monitor the soil, air, temperature, health, traffic, agriculture and so on [11]. It not only monitor the activities of human but also the habitats of wildlife and plants. The devices are connected to internet to monitor the natural disasters like tsunami or earthquake and give the warning signal or lightening. There is change in climate, temperature, rain, dust and so on. Some problem occurs due to increase in population and also due to industrial wastage. The result can be analyzed by using network, cloud storage, sensor, smart phone, internet of things and so on.

Jozef Glova .et.al proposed the paper on Business Models for the Internet of Things Environment [15]

In this paper machine to machine application is used for health monitoring and for traffic monitoring can be done through wired or short range communication like Bluetooth and other technologies. GPS/GPRS based devices is used for machine to machine communication. In Telecare the people can live with devices and sensors without depending on other devices. The sensors like movement sensor, fall detectors and activity hubs. The telecare devices use IoT technologies, it can be implemented efficiently using open standard technologies.

\section{III.Applications Of Internet Of Things}

Internet of things has many applications to make the human life easier, to avoid natural disasters, reduce the cost, reduce the time and so on. The internet of things is mainly based on internet and sensors. It is suitable even for portable devices and can be accessed by anyone from anyplace.

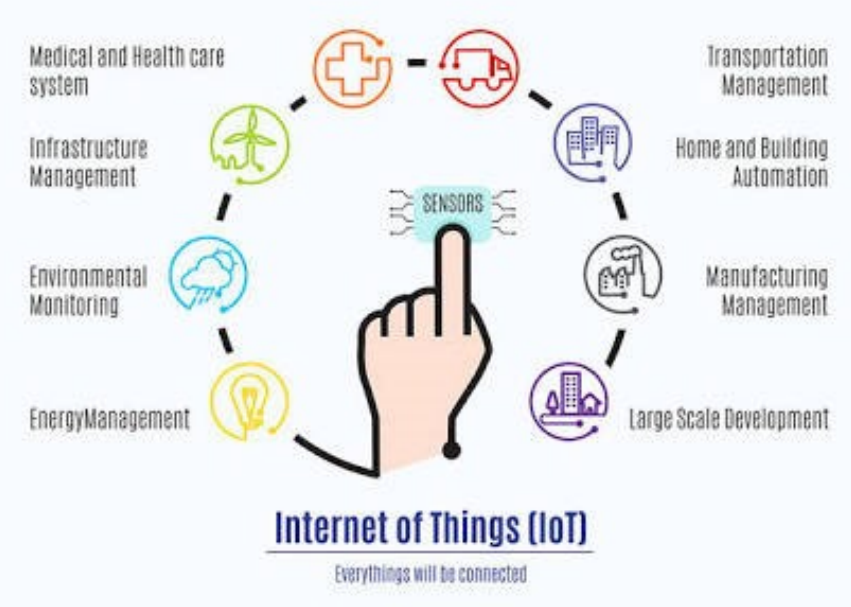

Fig 3: Applications of IoT

\section{Smart home}

The network connection is mandatory for IoT. Now days the Wi-Fi connection is provided in all the home. The network can be accessed by tv, smart phones, laptops and all other electronic devices. You can ON the switch of air conditioning even when you are not in home. Smart home application is used to save energy, time and cost. Initial implementation of the smart home application need high budget for the house owner. The smart home application includes voice control, intelligent control, burglary prevention, remote health monitoring and so on. The smart home applications need some components to make a smart home system. They are intelligent control, server portal, home automation and internal network. Smart home automation are lighting control, heating/cooling, air conditioning and ventilation, multi room system, solar energy system, personal safety system, home security, camera \& live video 
monitoring and intercom. Smart home has some benefits like enhanced comfort, energy saving, great safety and increased convenience.

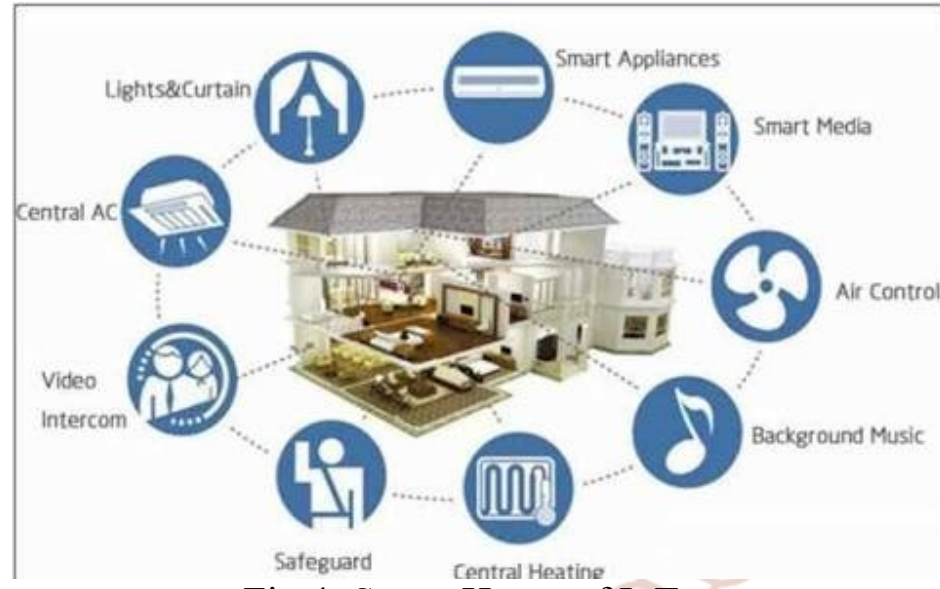

Fig 4: Smart Home of IoT

\section{Wearables}

Some wearable devices are integrated with IoT devices. The wearable devices consist of sensor, software used for collect the data about the user. Wearable devices receive pre-request from IoT. The user fitness, entertainment required and health are monitored by the wearable devices. It is later preprocessed to extract the useful information of user. The wearable devices should be small size, ultrapower and should have high energy efficiency. The wearable devices are smart glass, hearables and wrist wear.

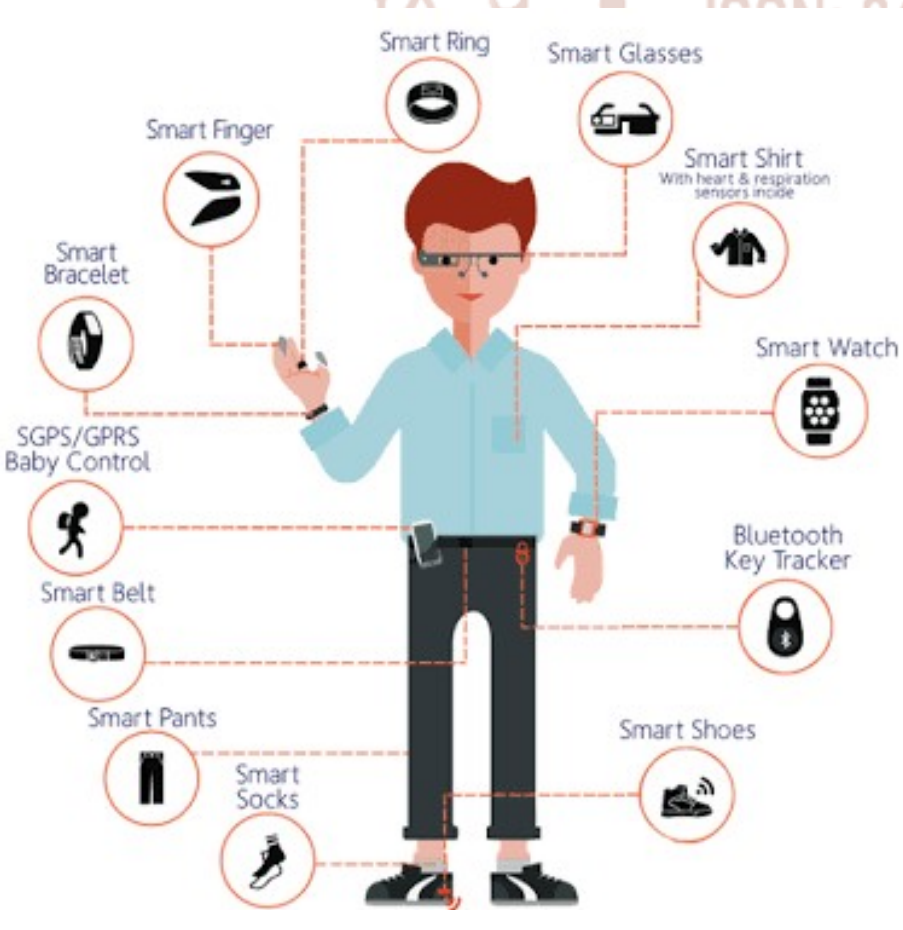

Fig 5: Wearable devices of IoT

\section{Connected cars}

The connected cars is one of the important application of smart cities. The connected cars consist of sensors and internet connection. It provide better service for passengers, it optimize the operation by its own and maintenance can be done by itself. The connected cars can manage multiple cars at a same time. It can monitor the fuel tracking, car leasing solution, connected vehicle sensors, traffic management, speed control, vehicle location tracking, workload management, real time car telematics tracking, fleet management and driver management.

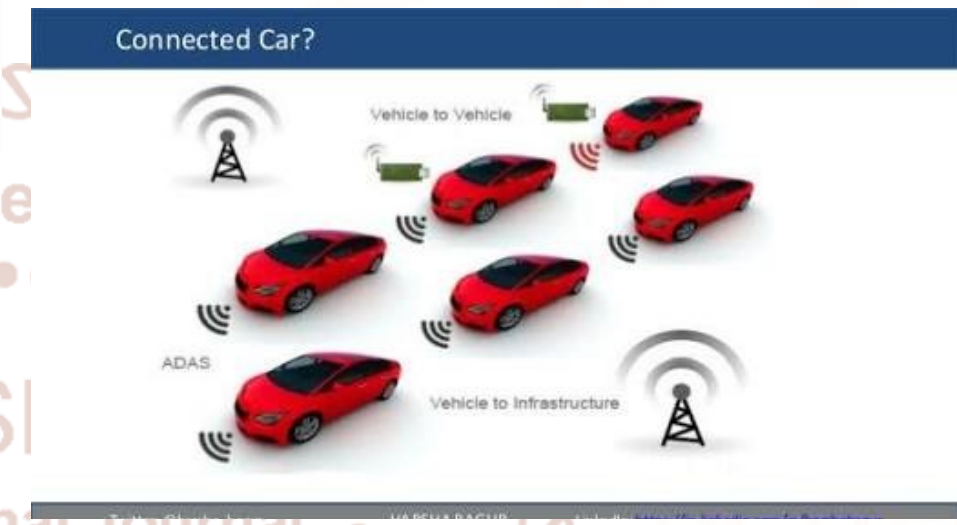

Fig 6: connected cars of IoT

\section{Smart cities}

Smart cities is one of the most important application in internet of things. In Smart cities there are several domains to be managed. It manages the urban security, energy management, automated transportation, water distribution and so on. IoT solves manage various problem arise in cities. It control the pollution, shortage of energy supplies, traffic congestion and so on. In the Smart cities the sensor is enabled with internet connection. It helps the user to have a better parking, reduce traffic, communicate with road side objects, better garbage collection and so on.

\section{IoT \& Smart City}

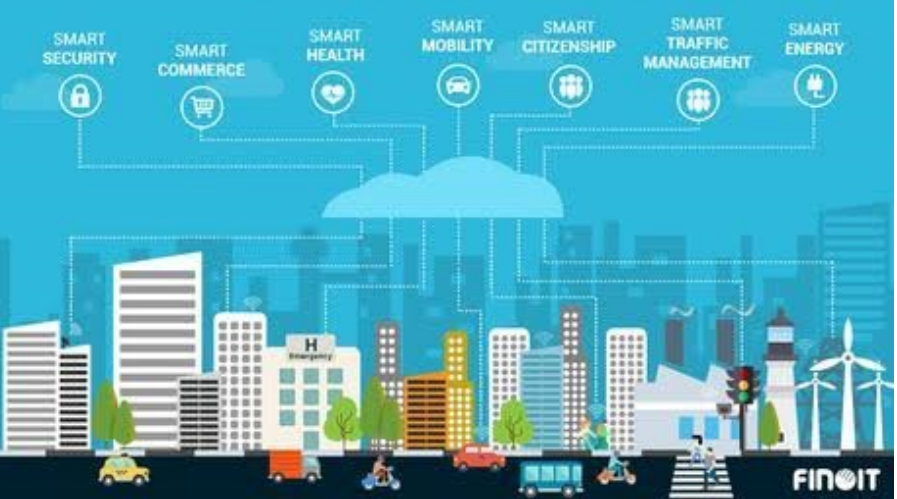

Fig 7: Smart city of IoT 


\section{Industrial internet}

In industries sensor is integrated, software is used to collect the data and big data is used to create the brilliant machines. Smart machine is more accurate and consistent than human communicate with data. IoT is used for controlling the quality and sustainability. It is used to exchange the goods between supplier and retailers, supply is increased with high efficiency and goods are tracked. It is used in oil and gas, manufacturing, mining and metals, aviation and so on.

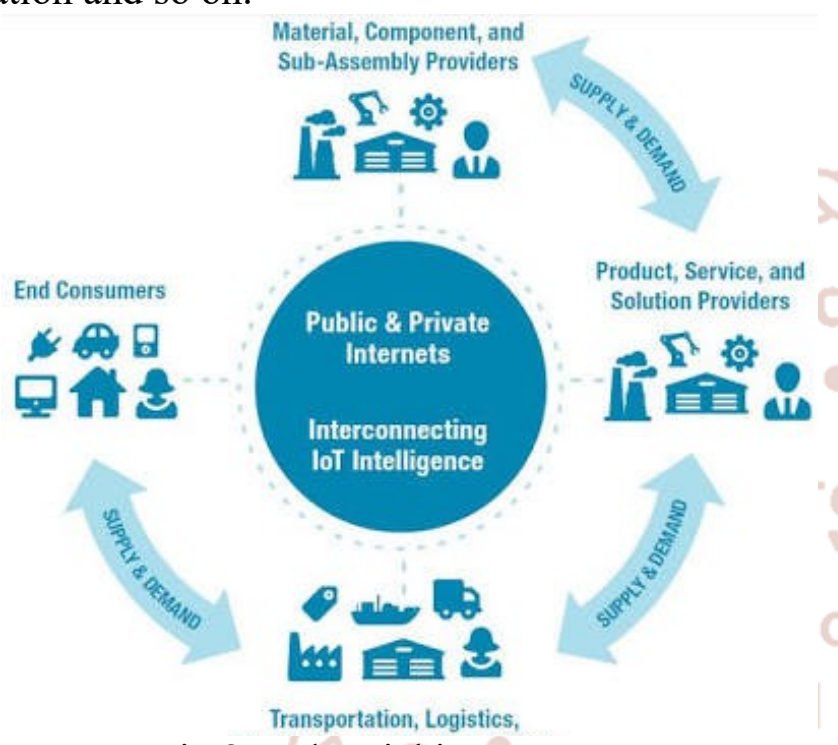

Fig 8: Industrial internet IoT

\section{Smart agriculture}

In agriculture the use of IoT is very essential. IoT is used in agriculture for monitoring the soil, controlling water, determine the level of fertilizer, monitor the plant growth, detect the infection and so on. It can be monitored using the sensors, software, hardware and few devices. The farmer can monitor the field, supply water from anywhere. There are some applications like precision farming, agriculture drones, livestock monitoring and smart greenhouse. It reduce the cost, time and effort of human. It is also called as precision agriculture.

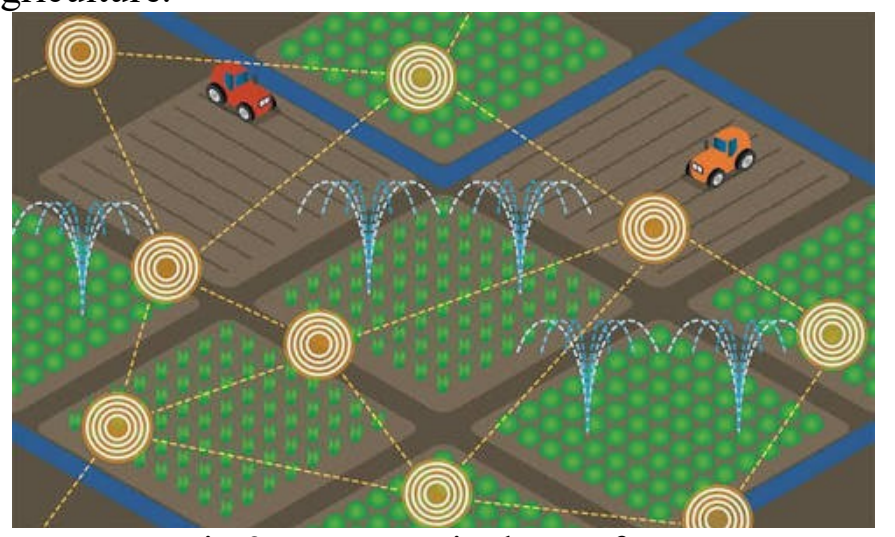

Fig 9: Smart agriculture of IoT

\section{PROPOSED SYSTEM}

There are many services can be done to this environment by IoT. The information are collected by sensor. The roadside sensors can collect the activities take place in roads. There is any issue take place in road it will be informed to respected higher authorities. Any animal met in an accident it is informed to blue cross. Likewise any plant affected by diseases in road side, those information are send to higher authorities. In the smart agriculture the collected information are send to farmer. There is any diseases spread in the farmland it is informed to farmer as well as the higher authorities of nearby agriculture specialist. There is any natural disaster is yet to arise the lightning and warning signal is produced in existing system but in proposed system the alert message is send to collector of that particular district, police station found nearby and also to few higher authorities. The waste management system is one of the important process in smart cities. The level of garbage container is overloaded the warning sound is produced. It helps to keep the city clean and hygienic. Vehicle tracking system is used to park the vehicle and reduce the traffic. In smart home application sensors provide security to home.

\section{Conclusion}

Internet of things provide many application to connect the human to object and human to human through internet. Each object is connected through internet it communicate the data to another object. Human can communicate with the object from anywhere at any time. Here the sensor is one of the important device used for communication. Now days the world gets more comfortable for human by IoT. In IoT two issues arise to affect the communication. The one issue is different networks coexist and the other issue is the big data the size of the data in IoT difficult to handle. There are some current issues like security, deliver of voice and video, address restriction and address restriction can affect the internet of things. The development of technologies can overcome these current issues. The IoT hardware can be reused. The sensor nodes can be replaced by another node but there is no need of replacing the softwares, data servers and radio communications. Internet of things can be used to monitor the agriculture, smart cities and some of the other important fields. It is used mainly for security purpose. In this paper some of the applications of IoT has discussed. 
International Journal of Trend in Scientific Research and Development (IJTSRD) ISSN: 2456-6470

\section{Reference}

1. VimalJerald, A., S. A. Rabara, and T. D. P. Bai. "Internet of things (IoT) based smart environment integrating various business applications. "International Journal of Computer Applications 128.128 (2015): 32-37.

2. Gubbi, Jayavardhana, et al. "Internet of Things (IoT): A vision, architectural elements, and future directions." Future generation computer systems 29.7 (2013): 1645-1660.

3. Rajguru, Shagufta, Swati Kinhekar, and Sandhya Pati. "Analysis of internet of things in a smart environment." Analysis 4.4 (2015).

4. Zeinab, Kamal Aldein Mohammed, and Sayed Ali Ahmed Elmustafa. "Internet of Things applications, challenges and related future technologies." World Scientific News 2.67 (2017): 126-148.

5. Hart, Jane K., and Kirk Martinez. "Toward an environmental Internet of Things." Earth and Space Science 2.5 (2015): 194-200.

6. Piyare, Rajeev. "Internet of things: ubiquitous home control and monitoring system using android based smart phone." International Journal of Internet of Things 2.1 (2013): 5-11. Atzori, Luigi, Antonio Iera, and Giacomo Morabito. "The internet of things: A survey." Computer networks 54.15 (2010): 2787-2805.

7. Jin, Jiong, et al. "An information framework for creating a smart city through internet of things." IEEE Internet of Things Journal 1.2 (2014): 112-121.

8. Da $\mathrm{Xu}, \mathrm{Li}, \mathrm{Wu} \mathrm{He}$, and Shancang Li. "Internet of things in industries: A survey." IEEE Transactions on industrial informatics 10.4 (2014): 2233-2243.

9. Gubbi, Jayavardhana, et al. "Internet of Things (IoT): A vision, architectural elements, and future directions." Future generation computer systems 29.7 (2013): 1645-1660.

10. Atzori, Luigi, Antonio Iera, and Giacomo Morabito. "The internet of things: A survey." Computer networks 54.15 (2010): 27872805.

11. Fang, Shifeng, et al. "An integrated system for regional environmental monitoring and management based on internet of things." IEEE Transactions on Industrial Informatics 10.2 (2014): 1596-1605.
12. Bandyopadhyay, Debasis, and Jaydip Sen. "Internet of things: Applications and challenges in technology and standardization." Wireless Personal Communications 58.1 (2011): 49-69. Miorandi, Daniele, et al. "Internet of things: Vision, applications and research challenges." $\mathrm{Ad}$ hoc networks 10.7 (2012): 1497-1516.

13. Glova, Jozef, Tomáš Sabol, and Viliam Vajda. "Business models for the internet of things environment." Procedia Economics and Finance 15 (2014): 1122-1129.

14. Kelly, Sean Dieter Tebje, Nagender Kumar Suryadevara, and Subhas Chandra Mukhopadhyay. "Towards the implementation of IoT for environmental condition monitoring in homes." IEEE Sensors Journal 13.10 (2013): 3846-3853.

15. Mainetti, Luca, Luigi Patrono, and Antonio Vilei. "Evolution of wireless sensor networks towards the internet of things: A survey." Software, Telecommunications and Computer Networks (SoftCOM), 2011 19th International Conference on. IEEE, 2011.

16. Zanella, Andrea, et al. "Internet of things for smart cities." IEEE Internet of Things journal 1.1 (2014): 22-32.

17. Neirotti, Paolo, et al. "Current trends in Smart City initiatives: Some stylised facts." Cities 38 (2014): 25-36.

18. Durand, Casey P., et al. "A systematic review of built environment factors related to physical activity and obesity risk: implications for smart growth urban planning." Obesity Reviews 12.5 (2011).

19. Kitchin, Rob. "Making sense of smart cities: addressing present shortcomings." Cambridge Journal of Regions, Economy and Society 8.1 (2015): 131-136.

20. Castro, Miguel, Antonio J. Jara, and Antonio FG Skarmeta. "Smart lighting solutions for smart cities." Advanced information networking and applications workshops (WAINA), 2013 27th international conference on. IEEE, 2013.

21. Al Nuaimi, Eiman, et al. "Applications of big data to smart cities." Journal of Internet Services and Applications 6.1 (2015): 25.

22. Lee, Jungwoo, and Hyejung Lee. "Developing and validating a citizen-centric typology for smart city 
services." Government Information Quarterly 31 (2014): S93-S105.

23. Cartelli, Antonio. "From smart cities to smart environment: Hints and suggestions for an ecology of the internet." International Journal of Digital Literacy and Digital Competence (IJDLDC) 3.4 (2012): 65-71.
24. Rachmawati, Tutik, and Priska Diah Pertiwi. "Smart Environment Program, Smart Way to Smart City." Policy \& Governance Review 1.1 (2017): 26-36.

25. Caragliu, Andrea, Chiara Del Bo, and Peter Nijkamp. "Smart cities in Europe." Journal of urban technology 18.2 (2011): 65-82. 